\title{
Supramolecular Luminescence from Oligofluorenol-Based Supramolecular Polymer Semiconductors
}

\author{
Guang-Wei Zhang ${ }^{1, \dagger}$, Long Wang ${ }^{1, \dagger}$, Ling-Hai Xie ${ }^{1, *}$, Jin-Yi Lin ${ }^{1}$ and Wei Huang ${ }^{1,2, *}$
}

1 Center for Molecular Systems and Organic Devices (CMSOD),

Key Laboratory for Organic Electronics \& Information Displays, Institute of Advanced Materials, Nanjing University of Posts \& Telecommunications, Nanjing 210046, China; E-Mails: iamgwzhang@njupt.edu.cn (G.-W.Z.); mrlong8@126.com (L.W.); y007091815@njupt.edu.cn (J.-Y.L.)

2 Jiangsu-Singapore Joint Research Center for Organic/Bio-Electronics \& Information Displays, Institute of Advanced Materials, Nanjing University of Technology, Nanjing 211816, China

$\dagger$ These authors contributed equally to this work.

* Authors to whom correspondence should be addressed; E-Mails: iamlhxie@njupt.edu.cn (L.-H.X.); iamwhuang@ @jupt.edu.cn (W.H.); Tel.: +68-187-5187-6505 (W.H.); Fax: +86-25-8586-6396 (W.H.).

Received: 29 August 2013; in revised form: 21 October 2013 / Accepted: 29 October 2013 / Published: 13 November 2013

\begin{abstract}
Supramolecular luminescence stems from non-covalent exciton behaviors of active $\pi$-segments in supramolecular entities or aggregates via intermolecular forces. Herein, a $\pi$-conjugated oligofluorenol, containing self-complementary double hydrogen bonds, was synthesized using Suzuki coupling as a supramolecular semiconductor. Terfluorenol-based random supramolecular polymers were confirmed via concentration-dependent nuclear magnetic resonance (NMR) and dynamic light scattering (DLS). The photoluminescent spectra of the TFOH-1 solution exhibit a green emission band (g-band) at approximately $\sim 520 \mathrm{~nm}$ with reversible features, as confirmed through titration experiments. Supramolecular luminescence of TFOH-1 thin films serves as robust evidence for the aggregates of g-band. Our results suggest that the presence of polyfluorene ketone defects is a sufficient condition, rather than a sufficient-necessary condition for the g-band. Supramolecular electroluminescence will push organic devices into the fields of supramolecular optoelectronics, spintronics, and mechatronics.
\end{abstract}


Keywords: luminescence; supramolecular polymers; polyfluorenes; hydrogen bonds; thin films

\section{Introduction}

Carbon is the smartest element in the periodic table. In this century, organic/plastic electronics are impacting the human society through organic light-emitting devices (OLEDs), solar cells, thin film transistors, organic lasers, organic memory devices and so on, which have all attracted significant attention from not only scientists but also the industrial community. Smart organic devices will update complex organic matter and function into organic mechatronics that involves mechano-semiconductors, molecular consciousness and organic robotics in the coming era of consciousness ultimately. Over the last few decades, powerful organic syntheses and rational top-down molecular design have enabled significant progress in organic electronics and OLED that have been commercially available [1]. Up to date, a bottom-up chemical four-element theory that involves electronic structures, steric repulsions, conformational topology, and non-covalent attractions, has been extracted to guide the molecular design of organic/polymer semiconductors [2]. However, several big challenges remain in terms of low-cost thin film deposition procedures. Relative to energy-consumptive vacuum thermal evaporation technique, solution-processed organic devices face the challenges such as the uniform, repeatable and multilayer high-quality thin films owing to unpredictable molecular packing, hierarchical textiles, and complex condensed behaviors.

Noncovalent forces dominate the condensed behaviors of solution-processed organic thin films. Supramolecular analyses in organic/polymer semiconductors have become an complementary top-level tool for understanding organic devices, especially for solution-processable ones. Supramolecular approaches enables the tuning of the electronic structures and energy transfers effectively. Supramolecular functionalization that introduces diverse noncovalent moieties to $\pi$-conjugated organic/polymer semiconductors via the covalent linkages imparts appealing features such as soft-matter mechanical features, self-assembly, self-healing and stimulus-response behaviors, besides the intrinsic optoelectronic characters. Significant progress has been made in terns of mainchain-type supramolecular polymers via multiple hydrogen bonds to understand complex pathway of supramolecular polymerizations [3]. However, the interruption of their conjugation sometimes limit the electronic delocalization and worsen electron transport. The $\pi$-stacked polymers was coined as supramolecular organic semiconductors (SOSs) that have the unique supramolecular channels for the charge transfer of electrons and generation of exciton [4-6]. These supramolecular conductive channels exhibit the unique dynamics, reversible conformations, and stimulus-response features that can be adjusted and controlled via bulky groups. As a result, hindrance-functionalized stacked polymers exhibit a conformational switching feature with the potential application of resistive nonvolatile flash memories. Supramolecular $\pi$-conjugated polymers are alternative side-chain-type supramolecular polymer semiconductors (SPSs) [7], with the obvious advantages of both excellent electronic transport and molecular assembly, which opens the door to smart organic devices in the fields of supramolecular optoelectronic and mechatronics. 
Of the various supramolecular forces, hydrogen bonding is a pivotal role to bio-systems, supramolecular assemblies, and organic semiconductors. Various multiple hydrogen bonds have been designed and synthesized [8-14] via supramolecular chemistry. Our previous works, demonstrate the supramolecular functionalization of polyfluorene-based conjugated polymers via hydrogen bonding, to design poly(tertiary alcohol) as excellent gelators [15]. As a result, gelation becomes a concise standard, guiding the selection of solvents in organic optical inks, which are key component to spin-coating or inkjet printing techniques. Our results also show that non-covalent network precursors in the solution are crucial to the thin-film optoelectronic behaviors and morphologies. These results inspired us to explore the supramolecular luminescence that stems from supramolecular structures or aggregates, consisting of intermolecular active $\pi$-segments, which are reorganized via non-covalent forces. In addition, the green emission bands (g-band) of polyfluorenol have been transferred as g-bands in polyfluorene and are crucial to the stability and performance of blue polymer light-emitting diodes (PLEDs), which has hindered their commercialization [16]. By comparison to polymer semiconductors, low molecular weight organic molecules have advantages over polymers in terms of the their structure-property relationships $[17,18]$. In this article, we design oligomers to confirm that the polyfluorenol g-bands stem from superstructures of the backbone, rather than chemical ketone defects. Our results differ completely from a previous study of a terfluorene with a flurorenol in the middle position [19].

\section{Results and Discussion}

\subsection{Synthesis}

To obtain supramolecular luminescence and clarify the green emission bands of polyfluorenols, we used terfluorenol TFOH-1 (9'-(4-(octyloxy)phenyl)-9,9"-diphenyl-[2,2':7',2"-terfluorene]-9,9',9"-triol) as model supramolecular semiconductors and a bulky ter(diphylfluorene) TFO8 (9,9',9"-tris (4-(octyloxy)phenyl)-9,9',9"-triphenyl-2,2':7',2"-terfluorene), as the sterically hindered reference sample. The synthetic routes for these compounds are shown in Scheme 1. The fluorene tertiary alcohol monomer was synthesized via a Grignard reaction as previously reported [20]. The target oligofluorenol were synthesized via a palladium-catalyzed carbon-carbon Suzuki cross-coupling reaction with approximately $75 \%$ yield due to its tolerance to hydroxyl groups. The TFO8 control, which has no supramolecular hydrogen bonding, was synthesized via a $\mathrm{BF}_{3} \cdot \mathrm{OEt}_{2}$-mediated Friedel-Crafts reaction (BFR) [20] between oligofluorenol and (octyloxy)benzene with a yield of up to $90 \%$.

\subsection{Supramolecular Polymers and Aggregates in Solutions}

To gain insight into the supramolecular interactions of the designed tertiary alcohol, concentration-dependent nuclear magnetic resonance (NMR) studies were performed in different solvents. Figure 1 shows the ${ }^{1} \mathrm{H}$ NMR spectra of the TFO 8 control in $\mathrm{CDCl}_{3}$ (a), the solvent-dependent ${ }^{1} \mathrm{H}$ NMR spectra of $2 \mathrm{mg} / \mathrm{mL}$ TFOH-1 in both $\mathrm{CD}_{3} \mathrm{OD}$ (b) and in $\mathrm{CDCl}_{3}$ (c) and the concentration-dependent ${ }^{1} \mathrm{H}$ NMR spectra of TFOH-1 (c: $2 \mathrm{mg} / \mathrm{mL}$; d: $10 \mathrm{mg} / \mathrm{mL}$ ). TFO8 yields well-resolved proton signals. The NMR spectra for TFOH-1 in $\mathrm{CD}_{3} \mathrm{OD}$ yielded well-resolved proton 
signals with no obvious up-field shift relative to TFO8, which indicates there are weak $\pi-\pi$ stacking interactions between backbone chains owing to $\mathrm{CD}_{3} \mathrm{OD}-\mathrm{TFOH}-1$ hydrogen bonding complexes. Conversely, the aromatic proton signals for TFOH- 1 in $\mathrm{CDCl}_{3}$ (c-d) were shifted $(\Delta \delta \approx-0.08 \mathrm{ppm}$ ), relative to the aromatic protons in (a) and (b), which was attributed to the molecular packing of terfluorene due to interchain hydrogen bonding interactions [21,22]. In the NMR of the concentrated $10 \mathrm{mg} / \mathrm{mL}$ solution, the hydroxy hydrogens were shifted downfield ( $\Delta \delta \approx+0.06 \mathrm{ppm}$ ), which suggests the presence of double hydrogen bonds. Moreover, all of the signals broadened at high concentrations, which indicates supramolecular aggregates or non-covalent, random single-component supramolecular polymers with high molecular weight were present [23]. It was deduced that the hydrogen bonding and $\pi-\pi$ stacking interactions most likely dominated the aggregate behaviors for the TFOH-1 in solutions.

Scheme 1. Synthetic routes to TFOH-1 and the TFO8 control.

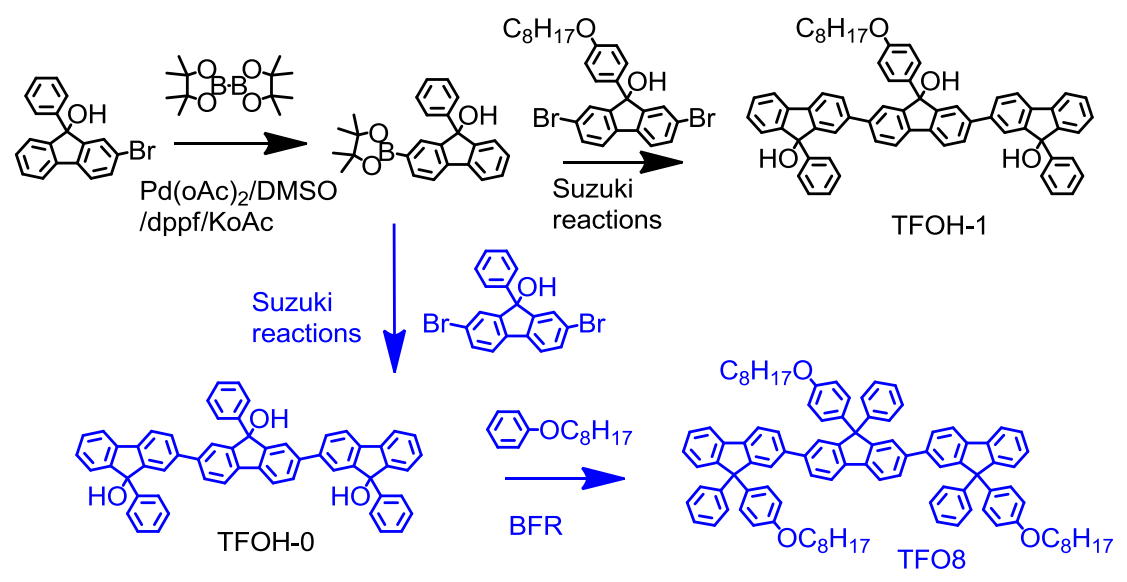

Figure 1. ${ }^{1} \mathrm{H}$ NMR spectra of TFO 8 in $\mathrm{CDCl}_{3}(\mathbf{a})$; ${ }^{1} \mathrm{H}$ NMR spectra of TFOH-1 in different solutions; (b) $\mathrm{CD}_{3} \mathrm{OD}$ and (c,d) $\mathrm{CDCl}_{3}$ and concentrations; (b,c) $2 \mathrm{mg} / \mathrm{mL}$ and (d) $10 \mathrm{mg} / \mathrm{mL}$.

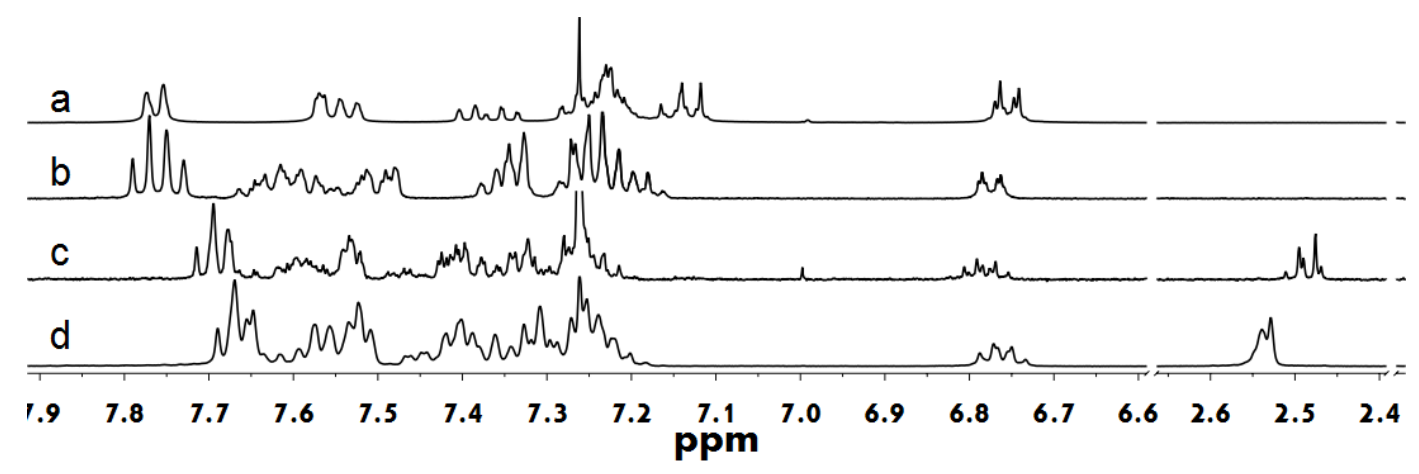

Dynamic light scattering (DLS) was employed to probe the molecular behaviors of TFOH-1 aggregates in chloroform at a concentration of $10 \mathrm{mg} / \mathrm{mL}$ (Figure 2). TFOH-1 possessed two sets of hydrodynamic radii. The first set is a narrow distribution of particles 2 to $9 \mathrm{~nm}$ in size that corresponds to the monomer and dimer structures. The second sets range from 90 to $190 \mathrm{~nm}$ and most likely arise from multiple associations between monomers to yield supramolecular aggregates. Hydroxy-based assemblies are consistent to previous observations [15]. 
Figure 2. Distribution of hydrodynamic radii $\left(R_{\mathrm{h}}\right)$ for the TFOH-1 aggregates (chloroform, $10 \mathrm{mg} / \mathrm{mL})$.

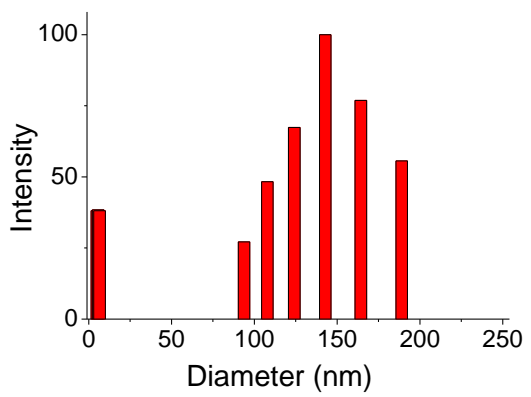

According to the NMR and DLS, TFOH-1 exhibited different molecular aggregates in various states as outlined in Figure 3. Dilute TFOH-1 molecules in chloroform are dispersed individually as depicted in Figure 3A. Concentrated TFOH-1 in the $\mathrm{CH}_{3} \mathrm{OH}$ has no interactions between the terfluorene molecular, as shown in Figure 3B, due to the formation of solvent-TFOH-1 complexes that are only expected to slightly change the conjugation length. However, concentrated TFOH-1 in an aprotic solvent, such as chloroform, aggregates via intermolecular hydrogen bonds to form new supramolecular entities as shown in Figure 3C. Therefore, random non-covalent, single-component supramolecular polymers are thought to form an elastic cross-linked network of terfluorenes at room temperature. In this scenario, the optoelectronic behavior of TFOH-1 can be modified via the solvent, solvent concentration, and other external additives or conditions.

Figure 3. Schematic illustration of the supramolecular TFOH-1 aggregate (red cross: TFOH-1 molecules; blue line: H-bonding). (A) Dilute TFOH-1 molecules in chloroform; (B) Concentrated TFOH-1 in the $\mathrm{CH}_{3} \mathrm{OH}$; (C) Concentrated TFOH-1 in an aprotic solvent.
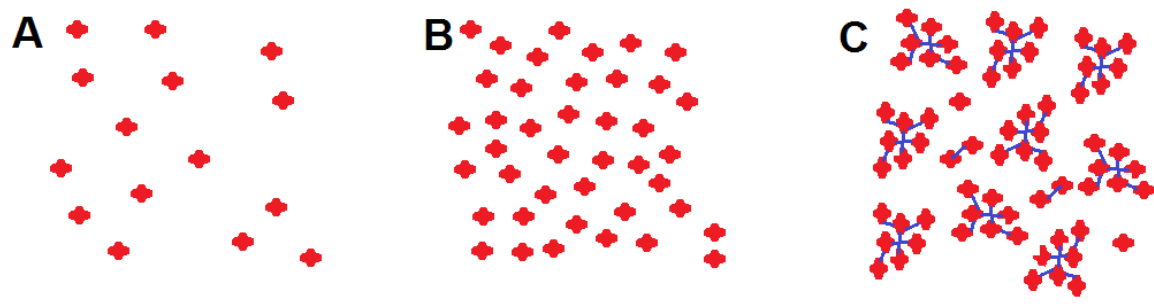

\subsection{Supramolecular Luminescence in Solution and Thin Films}

In this supramolecular framework, TFOH-1 photoluminescence spectra and TFO8 control were systemically characterized in different solution and thin films as shown in Figure 4. Based on the NMR and DLS results discussed above, the TFOH-1 supramolecular polymer aggregates that form at high concentrations, result from intermolecular hydrogen bonding. The concentration-dependent PL spectra of TFOH-1 and TFO8 are shown in Figure 4A,B. Dilute TFOH-1 in toluene yields emission peaks at 398 and $420 \mathrm{~nm}$ with a shoulder at $448 \mathrm{~nm}$ that was attributed to the main terfluorene chains [24], similarly, the dilute TFO8 solution yields peaks at 397 and $419 \mathrm{~nm}$ with a shoulder at $443 \mathrm{~nm}$. However, the PL spectra of concentrated TFOH-1 in toluene only possessed two emission peaks at 423 and $524 \mathrm{~nm}$, which was an obvious difference different from the TFO8 solution with the same concentration. No green band emissions (g-bands) were detected in the concentrated TFO8, even at 
concentrations of up to $15 \mathrm{mg} / \mathrm{mL}$. Increasing the concentration $(>0.01 \mathrm{mg} / \mathrm{mL})$ quenches the high band emission at approximately $398 \mathrm{~nm}$ and leaves only the emission peak at approximately $420 \mathrm{~nm}$. Additionally, the emission peak at $423 \mathrm{~nm}$ did not shift after increasing the concentration to $12 \mathrm{mg} / \mathrm{mL}$. The unique emission behavior of TFOH-1 was most likely caused by an energy transfer from isolated terfluorenes to the supramolecular aggregates via hydrogen bond interactions. These results are consistent with the above NMR spectra and support the conclusion that the average $R_{\mathrm{h}}$ of $18-41 \mathrm{~nm}$ from the DLS analysis resulted from hydrogen bonded aggregates. TFO8 possessed a stable blue emission due to the excellent steric hindrance from bulky diarylfluorenes [17].

Figure 4. Photoluminescence spectra. (A) Concentration dependent PL spectra of TFOH-1 in toluene $(0.01-12 \mathrm{mg} / \mathrm{mL}$ ) with photographs (a for $12 \mathrm{mg} / \mathrm{mL}$; b for $0.01 \mathrm{mg} / \mathrm{mL}$ ); (B) Concentration dependent PL spectra of TFO8 in toluene $(0.01-15 \mathrm{mg} / \mathrm{mL})$; (C) PL spectra of TFOH-1 in toluene $(8 \mathrm{mg} / \mathrm{mL})$ with differing methanol concentrations $(0 \%-10 \%)$ with photographs (a for methanol $=0$; $b$ for methanol $=10 \%)$; (D) PL spectra of the films before and after annealing and photographs of thin films after annealing (a for TFOH-1; b for TFO8).
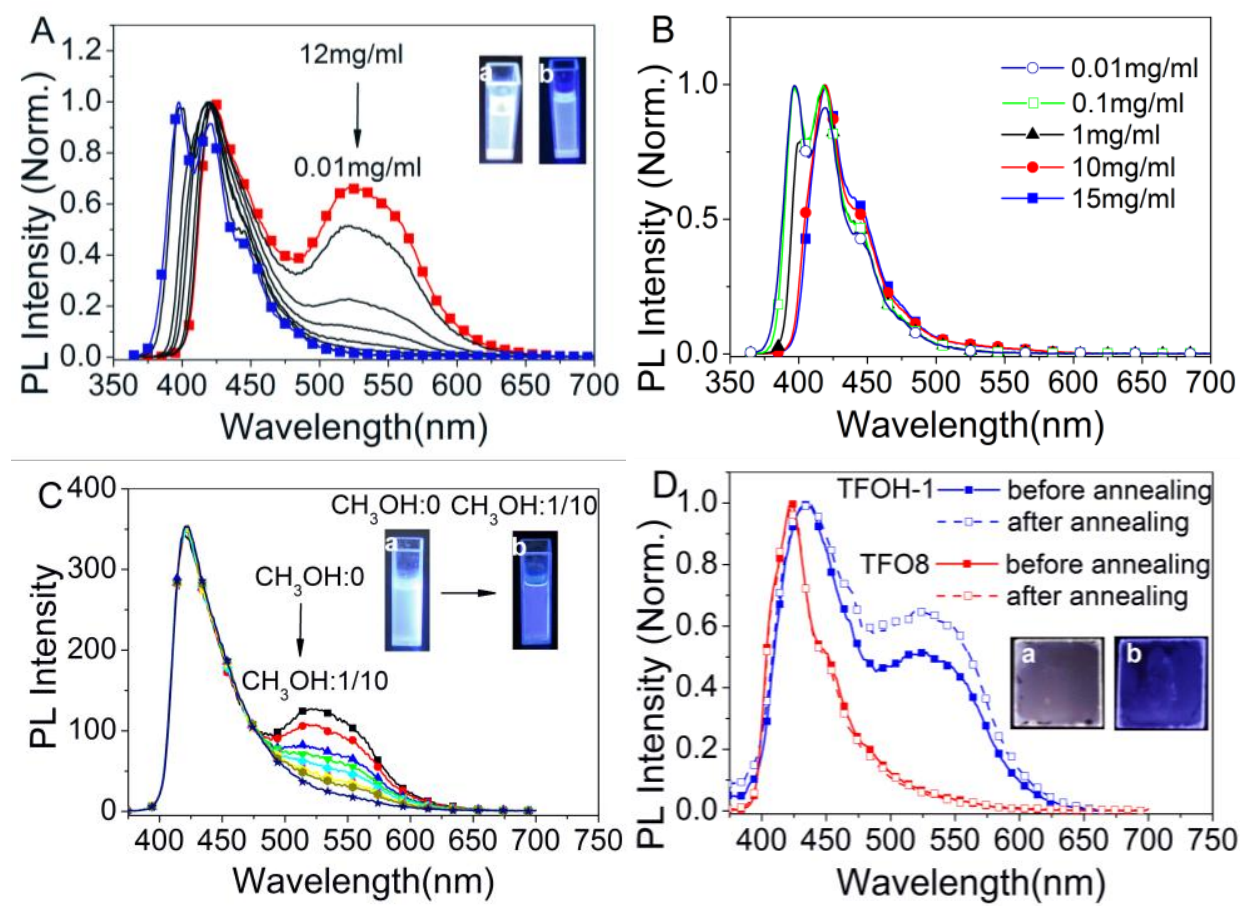

The supramolecular luminescence behavior of concentrated TFOH-1 in toluene was supported by a titration experiment that involved adding differing $\mathrm{CH}_{3} \mathrm{OH}$ concentrations (0\%-10\%) to a TFOH-1 in toluene solution $(8 \mathrm{mg} / \mathrm{mL})$ [21]. In contrast to TFOH-1 in toluene without methanol, the TFOH-1 emission spectra after adding $10 \% \mathrm{CH}_{3} \mathrm{OH}$ exhibited only one peak at $422 \mathrm{~nm}$, which indicates that the terfluorenes formed a well-dissolved isotropic phase corresponding to the NMR analysis. The reversibility of the luminescent supramolecular g-bands in solution strongly supports an aggregate mechanism over the ketone defects mechanism supported by many groups [19,25,26]. The PL spectra of TFOH-1 and TFO8 films spin-coated from toluene solvent $(10 \mathrm{mg} / \mathrm{mL})$ were investigated before and after annealing (Figure 4D). Emission spectrum of TFO8 contained a single peak at $435 \mathrm{~nm}$ with a 
shoulder peak at $450 \mathrm{~nm}$. However, similar to its solution emission spectra, the PL spectrum of the TFOH-1 film contained two peaks at $435 \mathrm{~nm}$, the high energy regime associated with single chain emissions, and at $526 \mathrm{~nm}$, which was attributed to TFOH-1 hydrogen bond aggregates. This phenomenon increased significantly after annealing. The supramolecular green emissions supported the aggregate mechanism [27-29] reported by the Tagawa group [30] and our previous results [31]. It is thought that self-constructed supramolecular structures are stable in the spin-coated thin films. These observations all imply the energy transfer from the high-energy regime (individual TFOH-1 chains luminophores in the isotropic phase) to a low-energy entities (intermolecular hydrogen bonded supramolecular polymers) to form an organic bulk homojunction thin film with potential organic electronics applications.

\section{Experimental Section}

\subsection{Chemicals}

All of the solvents and reagents were purchased from commercial suppliers and used without further purification unless otherwise noted. All products were purified by flash column chromatography using Kanto Silica Gel (Kanto Chemical Co., Inc., Xuhui District, Shanghai, China) 60N (40-63 $\mu \mathrm{m})$. Spectrochemical-grade solvents were used for the optical measurements. Palladium(II) acetate, tetra(triphenylphosphine)palladium(II), 1,1'-bis(diphenylphosphino)ferrocene (dppf), 2,7-dibromo-9-fluorenone, 2-bromo-9-fluorenone, bromobenzene, 1-bromo-4-(octyloxy) benzene, and 2,2'-bithiophene were obtained from Aldrich Chemical Co. (Xuhui District, Shanghai, China). Borontrifluoride etherate, potassium carbonate, magnesium sulfate, chloroform and toluene were purchased from Sinopharm Chemical Reagent Co, Ltd (Nanjing, Jiangsu, China) and were used without further purification. Dichloromethane was dried using anhydrous sodium at room temperature. THF and toluene were dried over the sodium benzophenone ketyl anion radical and distilled under a dry nitrogen atmosphere immediately prior to use. The following 2,7-Dibromo-9(4-(octyloxy)phenyl)-fluoren-9-ol (DBrOOPFOH), 2,7-dibromo-9-phenyl-fluoren-9-ol (DBrPFOH), 2-bromo-9-phenyl-fluoren-9-ol (BrPFOH) and, 2-(4,4,5,5-tetramethyl-1,3,2-dioxaborolan-2-yl)-9phenylfluoren-9-ol (TMB-PFOH) were obtained according to previously published protocols $[15,25]$.

\subsection{Characterization}

The ${ }^{1} \mathrm{H}$ NMR and ${ }^{13} \mathrm{C}$ NMR spectra were recorded in $d-\mathrm{CDCl}_{3}$ or $d-\mathrm{CD}_{3} \mathrm{OD}$ containing a tetramethylsilane (TMS) interval standard, using a Bruker $400 \mathrm{MHz}$ spectrometer. The mass spectra were recorded on a Shimadzu GC-MS 2010 PLUS. The MALDI-TOF MS spectra were recorded in the reflective mode using substrates. The absorption spectra were measured using a Shimadzu UV-3150 spectrometer (Shimadzu Corporation, Nanjing, Jiangsu, China) at $25^{\circ} \mathrm{C}$, and the emission spectra were recorded using a Shimadzu RF-530XPC luminescence spectrometer (Shimadzu Corporation, Nanjing, Jiangsu, China) after excitation at the absorption maxima. Dynamic light scattering (DLS, Zetasizer Nano-ZS) measurements were performed at a wavelength of $633 \mathrm{~nm}$ using a laser light source at room temperature. The DLS measurements were generally repeated at least three times, and the average values were reported. 


\subsection{Synthesis}

3.3.1. Synthesis of 2-(4,4,5,5-tetramethyl-1,3,2-dioxaborolan-2-yl)-9-phenylfluoren-9-ol (TMB-PFOH) from 2-bromo-9-phenylfluoren-9-ol (BrPFOH)

2-Bromo-9-phenylfluoren-9-ol (3.36 g, 10 mmol, 1 eq), 4,4,4',4',5,5,5',5'-octamethyl-2,2'-bi(1,3,2dioxaborolane) (3.04 g, $12 \mathrm{mmol}, 1.2 \mathrm{eq})$, palladium(II) acetate (66 mg, $0.3 \mathrm{mmol}, 0.03 \mathrm{eq}$ ), potassium acetate $(2.94 \mathrm{~g}, 30 \mathrm{mmol}, 3 \mathrm{eq})$, a 1,1'-bis(diphenylphosphino)ferrocene (dppf) ligand (0.332 g, $0.6 \mathrm{mmol}, 0.06 \mathrm{eq})$ were added to a three-necked Schlenk flask (150 mL). The flask was evacuated and back-filled with nitrogen more than three times before injecting with DMSO (30 $\mathrm{mL})$ through a syringe. The mixture was heated to $80{ }^{\circ} \mathrm{C}$ and stirred for $4 \mathrm{~h}$. Water $(150 \mathrm{~mL})$ was then added to quench the reaction. The phases were separated, and the aqueous phase was extracted with dichloromethane. The combined dichloromethane layers were washed and dried $\left(\mathrm{MgSO}_{4}\right)$. After removing the solvent, the remaining crude product was purified by silicon gel chromatography (petroleum ether-dichloromethane) to afford a pale yellow powder $(3.0 \mathrm{~g}, 79 \%)$. GC-MS $(\mathrm{m} / \mathrm{z})$ : calcd. For $\mathrm{C}_{25} \mathrm{H}_{25} \mathrm{BO}_{3}: 384.2\left[\mathrm{M}^{+}\right]$; Found: 384. ${ }^{1} \mathrm{H}$ NMR (400 MHz, $\left.\mathrm{CDCl}_{3}\right) \delta 7.84(\mathrm{dd}, J=7.5,0.8 \mathrm{~Hz}, 1 \mathrm{H})$, $7.77(\mathrm{~s}, 1 \mathrm{H}), 7.69(\mathrm{t}, J=7.1 \mathrm{~Hz}, 2 \mathrm{H}), 7.41-7.36(\mathrm{~m}, 3 \mathrm{H}), 7.36(\mathrm{~d}, J=1.3 \mathrm{~Hz}, 1 \mathrm{H}), 7.33(\mathrm{~s}, 1 \mathrm{H})$, $7.31(\mathrm{~s}, 1 \mathrm{H}), 7.29(\mathrm{q}, J=2.3 \mathrm{~Hz}, 1 \mathrm{H}), 7.24(\mathrm{dt}, J=5.8,2.0 \mathrm{~Hz}, 2 \mathrm{H}), 7.21(\mathrm{~d}, J=3.6 \mathrm{~Hz}, 1 \mathrm{H})$, $2.47(\mathrm{~s}, 1 \mathrm{H}), 1.31(\mathrm{~s}, 13 \mathrm{H}) .{ }^{13} \mathrm{C}$ NMR $\left(101 \mathrm{MHz}, \mathrm{CDCl}_{3}\right) \delta 149.73,142.61,139.33,136.02,129.07$, $128.98,128.22,127.13,125.52,124.85,120.52$, 119.47, 83.86, 83.63, 25.03, 24.99, 24.75 (Figure S1).

\subsubsection{Synthesis of TFOH-1 via Suzuki coupling reaction}

A typical preparation procedure is as follows: 2,7-Dibromo-9-(4-(octyloxy)phenyl)-fluoren-9-ol (0.54 g, 1 mmol, 1 eq), 9-phenyl-2-(4,4,5,5-tetramethyl-1,3,2-dioxaborolan-2-yl)-fluoren-9-ol (TMB-PFOH) (0.84 g, $2.4 \mathrm{mmol}, 2.4 \mathrm{eq}$ ), tetra(triphenylphosphine) palladium (0) (35 mg, $0.03 \mathrm{eq})$ were added to a three-necked Schlenk flask $(150 \mathrm{~mL})$. The flask was evacuated and back-filled with nitrogen atmosphere more than three times before injecting with degassed toluene $(30 \mathrm{~mL})$ and an aqueous $\mathrm{K}_{2} \mathrm{CO}_{3}$ solution ( $2 \mathrm{M}, 5 \mathrm{~mL}, 10 \mathrm{eq}$ ) through a syringe. The mixture was heated to $90{ }^{\circ} \mathrm{C}$ and stirred for $48 \mathrm{~h}$. The solvent was removed under vacuum. The mixture was purified by silica gel chromatography $\left(\mathrm{CH}_{2} \mathrm{Cl}_{2}\right)$ to afford a pale yellow powder $(0.67 \mathrm{~g}, 75 \%)$. MALDI-TOF-MS $(\mathrm{m} / \mathrm{z})$ : calcd. For $\mathrm{C}_{65} \mathrm{H}_{54} \mathrm{O}_{4}: 898.4\left[\mathrm{M}^{+}\right]$; Found: 896.9 (Figure S2). ${ }^{1} \mathrm{H}$ NMR (400 MHz, $\mathrm{CDCl}_{3}$ ) $\delta 7.67$ $(\mathrm{dd}, J=11.3,5.5 \mathrm{~Hz}, 7 \mathrm{H}), 7.60-7.55(\mathrm{~m}, 4 \mathrm{H}), 7.52(\mathrm{t}, J=5.2 \mathrm{~Hz}, 5 \mathrm{H}), 7.48-7.43(\mathrm{~m}, 1 \mathrm{H})$, $7.72-7.14(\mathrm{~m}, 39 \mathrm{H}), 7.39(\mathrm{dd}, J=12.7,7.3 \mathrm{~Hz}, 5 \mathrm{H}), 7.31(\mathrm{ddd}, J=12.2,10.6,5.8 \mathrm{~Hz}, 7 \mathrm{H})$, $7.29-7.18(\mathrm{~m}, 10 \mathrm{H}), 6.76(\mathrm{dd}, J=15.1,6.5 \mathrm{~Hz}, 2 \mathrm{H}), 3.95-3.77(\mathrm{~m}, 2 \mathrm{H}), 2.53(\mathrm{~d}, J=4.2 \mathrm{~Hz}, 3 \mathrm{H})$, $1.71(\mathrm{dt}, J=14.5,7.1 \mathrm{~Hz}, 2 \mathrm{H}), 1.46-1.21(\mathrm{~m}, 13 \mathrm{H}), 0.87(\mathrm{dd}, J=7.2,3.6 \mathrm{~Hz}, 3 \mathrm{H}) .{ }^{13} \mathrm{C} \mathrm{NMR}(101 \mathrm{MHz}$, $\left.\mathrm{CDCl}_{3}\right) \delta 158.45,151.65,151.25,151.18,150.83,150.78,143.09,143.04,141.25,141.19,141.05$, $139.17,139.11,138.96,138.89,138.34,132.15,132.05,131.91,129.14,128.55,128.47,128.43$, $128.31,128.27,128.16,128.03,127.27,126.61,125.44,124.78,123.34,123.25,120.43,120.39$, 120.17, 114.29, 83.66, 83.63, 83.43, 67.94, 31.81, 29.35, 29.27, 29.23, 26.07, 26.05, 22.65, 14.10. Anal. calcd. For $\mathrm{C}_{65} \mathrm{H}_{54} \mathrm{O}_{4}$ : C, 86.83; H, 6.05; O, 7.12. Found: C, 87.01; H, 6.71; O, 7.01 (Figure S3). 


\subsubsection{Synthesis of 9,9',9"-triphenyl-[2,2':7',2"-terfluorene]-9,9',9"-triol (TFOH-0)}

5,5'-Bis(2,7-dibromo-9-(4-(octyloxy)phenyl)-fluoren-9-yl)-2,2'-bithiophene (1.214 g, $1 \mathrm{mmol}, 1 \mathrm{eq}$ ), 2-bromo-9-(4-(octyloxy)phenyl)-fluoren-9-ol (2.04 g, $4.4 \mathrm{mmol}, 4.4 \mathrm{eq})$, tetra(triphenylphosphine) palladium (0) (35 mg, $0.03 \mathrm{eq}$ ) were added to a three-necked Schlenk flask (150 mL). The flask was evacuated and back-filled with nitrogen atmosphere at least three times before injecting with degassed toluene $(30 \mathrm{~mL})$ and aqueous $\mathrm{K}_{2} \mathrm{CO}_{3}(2 \mathrm{M}, 5 \mathrm{~mL}, 10 \mathrm{eq})$ through a syringe. The mixture was heated to $90{ }^{\circ} \mathrm{C}$ and stirred for two days. The solvent was removed under vacuum. The mixture was purified by silica gel chromatography $\left(\mathrm{CH}_{2} \mathrm{Cl}_{2}\right)$ to afford a pale yellow powder $(0.99 \mathrm{~g}, 61 \%)$. $\mathrm{Rf}=0.24$. MALDI-TOF-MS $(\mathrm{m} / \mathrm{z})$ : calcd. For $\mathrm{C}_{57} \mathrm{H}_{38} \mathrm{O}_{3}: 770\left[\mathrm{M}^{+}\right]$; Found: 768.1. ${ }^{1} \mathrm{H}$ NMR $\left(400 \mathrm{MHz}, \mathrm{CDCl}_{3}\right) \delta$ $7.67(\mathrm{t}, J=6.5 \mathrm{~Hz}, 6 \mathrm{H}), 7.57(\mathrm{t}, J=7.9 \mathrm{~Hz}, 4 \mathrm{H}), 7.52(\mathrm{t}, J=4.9 \mathrm{~Hz}, 4 \mathrm{H}), 7.39(\mathrm{dd}, J=13.5,7.1 \mathrm{~Hz}$, $8 \mathrm{H}), 7.31(\mathrm{t}, J=7.2 \mathrm{~Hz}, 3 \mathrm{H}), 7.24(\mathrm{dt}, J=17.9,8.1 \mathrm{~Hz}, 12 \mathrm{H}), 2.54(\mathrm{~d}, J=18.5 \mathrm{~Hz}, 3 \mathrm{H})$. ${ }^{13} \mathrm{C}$ NMR $\left(101 \mathrm{MHz}, \mathrm{CDCl}_{3}\right) \delta 151.24,151.17,150.78,150.74,143.03,142.98,141.26,141.21$, $141.12,141.07,139.15,139.10,138.99,138.93,138.46,129.17,128.50,128.37,128.32,128.28$, $128.23,128.17,128.11,128.04,127.29,125.43,124.78,123.35,123.31,120.49,120.42,120.19$, $83.67,83.63$.

\subsubsection{Synthesis of 9,9',9"-tris(4-(octyloxy)phenyl)-9,9',9"-triphenyl-2,2':7',2"-terfluorene (TFO8)}

A $\mathrm{BF}_{3} \cdot \mathrm{OEt}_{2}$ complex $(0.06 \mathrm{~mL}, 0.5 \mathrm{mmol})$ solution in dichloromethane $(2 \mathrm{~mL})$ was added drop-wise to a TFOH $(0.385 \mathrm{~g}, 0.5 \mathrm{mmol}, 1 \mathrm{eq})$ and (octyloxy)benzene $(1.03 \mathrm{~g}, 5 \mathrm{mmol}, 10 \mathrm{eq})$ mixture in dichloromethane $(10 \mathrm{~mL})$. This reaction mixture was stirred at room temprature $\left(25{ }^{\circ} \mathrm{C}\right)$ under nitrogen until no starting material was detectable by TLC (approximately $10 \mathrm{~min}$ ). Ethanol $(10 \mathrm{~mL})$ and water $(10 \mathrm{~mL})$ were successively added to quench the reaction. The phases were then separated, and the aqueous phase was extracted with dichloromethane. The combined dichloromethane layers were washed and dried $\left(\mathrm{MgSO}_{4}\right)$. After removing the solvent, the remaining crude product was purified by silicon gel chromatography (petroleum ether) to yield a white product. The yield of 9,9',9"tris(4-(octyloxy)phenyl)-9,9',9"-triphenyl-2,2':7',2"-terfluorene (TFO8) was 90\%. MALDI-TOF-MS $(\mathrm{m} / \mathrm{z})$ : calcd. For $\mathrm{C}_{99} \mathrm{H}_{98} \mathrm{O}_{3}: 1334.8\left[\mathrm{M}^{+}\right]$; Found: 1334.1 (Figure S4). ${ }^{1} \mathrm{H}$ NMR $\left(400 \mathrm{MHz}, \mathrm{CDCl}_{3}\right.$ ) $\delta 7.76(\mathrm{~d}, J=7.8 \mathrm{~Hz}, 6 \mathrm{H}), 7.55(\mathrm{dd}, J=12.3,5.2 \mathrm{~Hz}, 8 \mathrm{H}), 7.36(\mathrm{ddd}, J=9.9,8.5,4.3 \mathrm{~Hz}, 4 \mathrm{H})$, $7.30-7.18(\mathrm{~m}, 21 \mathrm{H}), 7.17-7.11(\mathrm{~m}, 7 \mathrm{H}), 6.79-6.72(\mathrm{~m}, 6 \mathrm{H}), 3.89(\mathrm{t}, J=6.5 \mathrm{~Hz}, 6 \mathrm{H}), 1.78-1.69$ $(\mathrm{m}, 6 \mathrm{H}), 1.41(\mathrm{~d}, J=7.9 \mathrm{~Hz}, 6 \mathrm{H}), 1.35-1.22(\mathrm{~m}, 30 \mathrm{H}), 0.90-0.85(\mathrm{~m}, 10 \mathrm{H}) .{ }^{13} \mathrm{C} \mathrm{NMR}(101 \mathrm{MHz}$, $\left.\mathrm{CDCl}_{3}\right) \delta 157.98,157.95,152.42,152.16,151.83,146.19,146.15,140.85,140.83,139.68,139.30$, $138.89,137.60,137.57,129.20,128.31,128.24,128.18,128.15,127.68,127.43,126.74,126.66$, $126.61,126.17,124.74,120.37,120.32,120.20,114.19,114.14,67.91,65.02,64.94,31.82,29.37$, 29.32, 29.25, 26.09, 22.67, 14.11. Elem. anal. calcd. For $\mathrm{C}_{99} \mathrm{H}_{98} \mathrm{O}_{3}: \mathrm{C}, 89.01 ; \mathrm{H}, 7.39 ; \mathrm{O}, 3.59$. Found: C, 90.10; H, 7.56; O, 3.53 (Figure S5).

\section{Conclusions}

We carried out supramolecular approaches to clarify the origin of green emission bonds (g-bands) and discover the phenomenon of supramolecular luminescence in oligo/polyfluorenes and their PLEDs. An oligofluorenol-based, supramolecular polymer semiconductor with sterically hindered 
oligofluorenes was designed and synthesized via a Suzuki reaction. A variety of evidence for an aggregate g-band mechanism for oligofluorene-based, supramolecular conjugated oligomers was provided using solvent- or concentration-dependent nuclear magnetic resonance (NMR), dynamic light scattering (DLS) and photoluminescence spectra. The reversibility of the TFOH-1 g-bands in toluene via methanol titration, suggests that random supramolecular polymers or aggregates were generated by cooperative interchain hydrogen bonding and $\pi-\pi$ stacking interactions. Therefore, our results strongly suggest that ketone defects are only a sufficient condition of g-bands, rather than a sufficient-necessary condition. Supramolecular electroluminescence will open a new door to organic devices in supramolecular optoelectronics.

\section{Acknowledgments}

This work was supported by the National Natural Science Funds for Excellent Young Scholar (21322402), The Program for New Century Excellent Talents in University (NCET-11-0992), National Natural Science Foundation of China (61106058, 51273092, 20974046, 20774043, 21274064, 51173081, 50428303, 61136003), and the Natural Science Foundation of Jiangsu Province (BK2011761, No. 11KJB510017, No. BK2008053, No. BK2009025, No. 10KJB510013 and No. BZ2010043). Funding of Jiangsu Innovation Program for Graduate Education (CXLX13_450). Ling-Hai Xie thanks the Jiangsu Overseas Research \& Training Program for University Prominent Young \& Middle-aged Teachers and Presidents. We are thankful to Zhang Yang for the MALDI-TOF spectra and Wei Qi for the NMR spectra.

\section{Conflicts of Interest}

The authors declare no conflict of interest.

\section{References}

1. Xie, L.H.; Yin, C.R.; Lai, W.Y.; Fan, Q.L.; Huang, W. Polyfluorene-based semiconductors combined with various periodic table elements for organic electronics. Progr. Polym. Sci. 2012, $37,1192-1264$.

2. Xie, L.-H.; Chang, Y.-Z.; Gu, J.-F.; Sun, R.-J.; Li, J.-W.; Zhao, X.-H.; Huang, W. Design of organic/polymeric $\pi$-Semiconductors: The four-element principle. Acta Phys. Chim. Sin. 2010, 26, 1784-1794.

3. Abbel, R.; Schenning, A.P.H.J.; Meijer, E.W. Fluorene-based materials and their supramolecular properties. J. Polym. Sci. Part A 2009, 47, 4215-4233.

4. Yin, C.R.; Ye, S.H.; Zhao, J.; Yi, M.D.; Xie, L.H.; Lin, Z.Q.; Chang, Y.Z.; Liu, F.; Xu, H.; Shi, N.E.; et al. Hindrance-functionalized pi-Stacked polymer host materials of the cardo-type carbazole-fluorene hybrid for solution-processable blue electrophosphorescent devices. Macromolecules 2011, 44, 4589-4595.

5. Yin, C.-R.; Han, Y.; Li, L.; Ye, S.-H.; Mao, W.-W.; Yi, M.-D.; Ling, H.-F.; Xie, L.-H.; Zhang, G.-W.; Huang, W. Hindrance-functionalized [small pi]-stacked polymer based on 
polystyrene with pendent cardo groups for organic electronics. Polym. Chem. 2013, 4, 2540-2545.

6. Xie, L.H.; Deng, X.Y.; Chen, L.; Chen, S.F.; Liu, R.R.; Hou, X.Y.; Wong, K.Y.; Ling, Q.D.; Huang, W. A pi-Stacked and conjugated hybrid based on Poly( $N$-vinylcarbazole) postfunctionalized with terfluorene for stable deep-blue hole-transporting materials. J. Polym. Sci. Pol. Chem. 2009, 47, 5221-5229.

7. Li, W.-J.; Liu, B.; Qian, Y.; Xie, L.-H.; Wang, J.; Li, S.-B.; Huang, W. Synthesis and characterization of diazafluorene-based oligofluorenes and polyfluorene. Polym. Chem. 2013, 4, 1796-1802.

8. Molla, M.R.; Ghosh, S. Hydrogen-bonding-mediated J-aggregation and white-light emission from a remarkably simple, single-component, naphthalenediimide chromophore. Chem. Eur. J. 2012, 18, 1290-1294.

9. Abbel, R.; Grenier, C.; Pouderoijen, M.J.; Stouwdam, J.W.; Leclère, P.E.L.G.; Sijbesma, R.P.; Meijer, E.W.; Schenning, A.P.H.J. White-light emitting hydrogen-bonded supramolecular copolymers based on $\pi$-conjugated oligomers. J. Am. Chem. Soc. 2008, 131, 833-843.

10. Brunsveld, L.; Folmer, B.J.B.; Meijer, E.W.; Sijbesma, R.P. Supramolecular polymers. Chem. Rev. 2001, 101, 4071-4098.

11. El-ghayoury, A.; Schenning, A.P.H.J.; van Hal, P.A.; van Duren, J.K.J.; Janssen, R.A.J.; Meijer, E.W. Supramolecular hydrogen-bonded oligo(p-phenylene vinylene) polymers. Angew. Chem. Int. Ed. 2001, 40, 3660-3663.

12. Ten Cate, A.T.; Kooijman, H.; Spek, A.L.; Sijbesma, R.P.; Meijer, E.W. Conformational control in the cyclization of hydrogen-bonded supramolecular polymers. J. Am. Chem. Soc. 2004, 126, 3801-3808.

13. Aida, T.; Meijer, E.W.; Stupp, S.I. Functional supramolecular polymers. Science 2012, 335, 813-817.

14. Zhao, J.F.; Li, Y.B.; Lin, Z.Q.; Xie, L.H.; Shi, N.E.; Wu, X.K.; Wang, C.; Huang, W. Molecule length directed self-assembly behavior of tetratopic oligomeric phenylene-ethynylenes end-capped with carboxylic groups by scanning tunneling microscopy. J. Phys. Chem. C 2010, 114, 9931-9937.

15. Lin, J.; Yu, Z.; Zhu, W.; Xing, G.; Lin, Z.; Yang, S.; Xie, L.; Niu, C.; Huang, W. A [small $\pi$ ]-conjugated polymer gelator from polyfluorene-based poly(tertiary alcohol) via the hydrogen-bonded supramolecular functionalization. Polym. Chem. 2013, 4, 477-483.

16. Liang, J.; Qian, Y.; Xie, L.-H.; Shi, N.-E.; Chen, S.-F.; Deng, X.-Y.; Huang, W. Spectral stability of polyfluorene-based semiconductors. Acta Phys. Chim. Sin. 2010, 26, 946-963.

17. Xie, L.H.; Hou, X.Y.; Hua, Y.R.; Huang, Y.Q.; Zhao, B.M.; Liu, F.; Peng, B.; Wei, W.; Huang, W. An effective strategy to tune supramolecular interaction via a spiro-bridged spacer in oligothiophene-S,S-dioxides and their anomalous photoluminescent behavior. Org. Lett. 2007, 9 , 1619-1622.

18. Wallace, J.U.; Chen, S.H. Fluorene-Based Conjugated Oligomers for Organic Photonics and Electronics. In Polyfluorenes; Scherf, U., Neher, D., Eds.; Springer: Berlin/Heidelberg, Germany, 2008; Volume 212, pp. 145-186. 
19. Egbert Zojer, A.P.; Hennebicq, E.; Beljonne, D.; Brédas, J.-L.; de Freitas, P.S.; Scherf, U.; List, E.J.W. Green emission from poly(fluorene)s: The role of oxidation. J. Chem. Phys. 2002, $117,6794$.

20. Xie, L.-H.; Hou, X.-Y.; Hua, Y.-R.; Tang, C.; Liu, F.; Fan, Q.-L.; Huang, W. Facile synthesis of complicated 9,9-diarylfluorenes based on BF3 center dot Et2O-mediated Friedel-Crafts reaction. Org. Lett. 2006, 8, 3701-3704.

21. Ajayaghosh, A.; George, S.J. First phenylenevinylene based organogels: Self-assembled nanostructures via cooperative hydrogen bonding and $\pi$-stacking. J. Am. Chem. Soc. 2001, 123, 5148-5149.

22. Chen, J.; Liu, H.; Weimer, W.A.; Halls, M.D.; Waldeck, D.H.; Walker, G.C. Noncovalent engineering of carbon nanotube surfaces by rigid, functional conjugated polymers. J. Am. Chem. Soc. 2002, 124, 9034-9035.

23. Fernández, G.; Pérez, E.M.; Sánchez, L.; Martín, N. Self-organization of electroactive materials: A head-to-tail donor-acceptor supramolecular polymer. Angew. Chem. Int. Ed. 2008, 47, 1094-1097.

24. Xie, L.H.; Hou, X.Y.; Tang, C.; Hua, Y.R.; Wang, R.J.; Chen, R.F.; Fan, Q.L.; Wang, L.H.; Wei, W.; Peng, B.; et al. Novel H-shaped persistent architecture based on a dispirlo building block system. Org. Lett. 2006, 8, 1363-1366.

25. List, E.J.W.; Guentner, R.; de Freitas, P.S.; Scherf, U. The effect of keto defect sites on the emission properties of polyfluorene-type materials. Adv. Mater. 2002, 14, 374-378.

26. Gong, X.; Iyer, P.K.; Moses, D.; Bazan, G.C.; Heeger, A.J.; Xiao, S.S. Stabilized blue emission from polyfluorene-based light-emitting diodes: Elimination of fluorenone defects. Adv. Funct. Mater. 2003, 13, 325-330.

27. Lemmera, U.; Heun, S.; Mahrta, R.F.; Scherfb, U.; Hopmeiera, M.; Siegnera, U. Aggregate fluorescence in conjugated polymers. Chem. Phys. Lett. 1995, 240, 373-378.

28. Bliznyuk, V.N.; Carter, S.A.; Scott, J.C.; Klärner, G.; Miller, R.D.; Miller, D.C. Electrical and photoinduced degradation of polyfluorene based films and light-emitting devices. Macromolecules 1998, 32, 361-369.

29. Zeng, G.; Yu, W.-L.; Chua, S.-J.; Huang, W. Spectral and thermal spectral stability study for fluorene-based conjugated polymers. Macromolecules 2002, 35, 6907-6914.

30. Koizumi, Y.; Seki, S.; Tsukuda, S.; Sakamoto, S.; Tagawa, S. Self-condensed nanoparticles of oligofluorenes with water-soluble side chains. J. Am. Chem. Soc. 2006, 128, 9036-9037.

31. Pei, J.; Liu, X.-L.; Chen, Z.-K.; Zhang, X.-H.; Lai, Y.-H.; Huang, W. First hydrogen-bondinginduced self-assembled aggregates of a polyfluorene derivative. Macromolecules 2002, 36, $323-327$.

(C) 2013 by the authors; licensee MDPI, Basel, Switzerland. This article is an open access article distributed under the terms and conditions of the Creative Commons Attribution license (http://creativecommons.org/licenses/by/3.0/). 